\title{
Who Participates in Content-Focused Teacher Professional Development? Evidence From a Large Scale Study
}

\author{
Eric Richter ${ }^{1 *}$, Mareike Kunter ${ }^{2}$, Alexandra Marx ${ }^{3}$ and Dirk Richter ${ }^{1}$ \\ ${ }^{1}$ Department Educational Sciences, University of Potsdam, Potsdam, Germany, ${ }^{2}$ Leibniz Institute for Research and Information in \\ Education, Frankfurt am Main, Germany, ${ }^{3}$ The German School Academy, Berlin, Germany
}

This study investigates the relationship between teacher quality and teachers' engagement in professional development (PD) activities using data on 229 German secondary school mathematics teachers. We assessed different aspects of teacher quality (e.g. professional knowledge, instructional quality) using a variety of measures, including standardised tests of teachers' content knowledge, to determine what characteristics are associated with high participation in PD. The results show that teachers with higher scores for teacher quality variables take part in more content-focused PD than teachers with lower scores for these variables. This suggests that teacher learning may be subject to a Matthew effect, whereby more proficient teachers benefit more from PD than less proficient teachers.

\section{OPEN ACCESS}

Edited by:

Eline Vanassche,

KU Leuven Kulak, Belgium

Reviewed by:

Paige K. Evans,

University of Houston, United States

Jan Elen,

KU Leuven, Belgium

*Correspondence:

Eric Richter

eric.richter@uni-potsdam.de

Specialty section:

This article was submitted to

Teacher Education,

a section of the journal

Frontiers in Education

Received: 08 June 2021

Accepted: 29 July 2021

Published: 10 August 2021

Citation:

Richter E, Kunter M, Marx A and Richter D (2021) Who Participates in Content-Focused Teacher Professional Development? Evidence

From a Large Scale Study.

Front. Educ. 6:722169.

doi: $10.3389 /$ feduc.2021.722169
Keywords: teacher learning, professional development, content knowledge, teacher quality, in-service training, Matthew effect, continuing education activities

\section{INTRODUCTION}

Teacher quality is of paramount importance for student outcomes, as a wealth of recent research has shown. Studies have also provided evidence of the effectiveness of programmes to improve teacher quality at the primary and secondary levels (Harris and Sass, 2011). Researchers generally agree that one of the most important ways to improve the quality of teachers and teaching is through professional development (PD) programmes (Darling-Hammond et al., 2017). In many countries, however, teachers are free to decide which and how many of the available PD programmes they want to attend (Eurydice, 2008). In this self-directed learning context, teachers themselves become key actors in efforts to improve the quality of teachers and teaching (Kwakman, 2003; van Eekelen et al., 2006). This raises the crucial question of why teachers take advantage of some types of PD and not others, and how teachers' attendance of PD programmes correlates with aspects of teacher quality.

Previous research on teachers' professional development focused on a number of different questions. One strand of the research sought to predict teachers' participation in PD to identify which teachers take advantage of PD offerings more than others. Studies have successfully demonstrated that psychological variables such as teacher motivation (Richter et al., 2019) predict the probability of attending PD programmes. The findings have shown that leaving the decision to participate in PD up to individual teachers has contributed to a situation in which not all teachers participate equally in professional learning. This unequal participation is likely to mean that teachers develop widely differing professional skills depending on the degree to which they take advantage of PD opportunities. This is an exploratory study that aims to identify the characteristics of teacher quality that are related to their uptake of professional development activities.

We apply a broad conceptualisation of teacher quality as the theoretical framework for this study. We analyse a comprehensive dataset of teachers that allows us to examine the links between various 
aspects of teacher quality, such as teaching quality and engagement in different PD activities over a 2 year period. The results of our study provide a better understanding of how teachers choose and organize their learning activities, and can also serve as a foundation for discussions on whether to make inservice training mandatory. We begin with a literature review related to theories of teacher participation in $\mathrm{PD}$, with regard to the Matthew effect. We then describe different aspects of teacher quality and provide an overview of studies showing how these aspects are related to teacher participation in PD.

\section{Mechanisms to Explain Differential Participation in Adult Education}

A number of different theoretical models and concepts have been proposed to explain teachers' uptake of PD. As we focus on the differential uptake of PD in our study, we developed our theoretical framework based on the Matthew effect, a concept that allows us to make predictions about individual PD activities based on teachers' individual characteristics. The concept goes back to a study by Merton (1968), which examined the unequal distribution of rewards within the scientific community. Merton noted that well-known scientists received more recognition than unknown scientists, even when their contributions to science were comparable, and called this psychosocial process "the Matthew effect." This phrase refers to a verse in the Gospel of St. Matthew ("For whoever has will be given more") and is used by scientists to describe the dynamics of individual growth rates in a particular characteristic and its relationship to the initial status of a given person (Petersen et al., 2011). More specifically, the Matthew effect can be used to describe how gaps in performance between persons with different levels of ability increase over time (Stanovich, 1986; Cain and Oakhill, 2011).

Walberg and Tsai (1983) applied the Matthew effect concept to educational research, using it to investigate differences in young adults' learning outcomes in science. Their study showed that early educational experiences predict educational activities and motivation in later life, suggesting cumulative advantages for young people from high SES families and with more years of education. This strand of research has expanded in the field of education. Starting from Stanovich (1986) - who described the role of reading experience as a driving mechanism for growth in reading - several studies examined differences in knowledge acquisition based on differences in learners' initial skill levels using the concept of the Matthew effect (Juel, 1988; Bast and Reitsma, 1998; Scarborough and Parker, 2003; Cain and Oakhill, 2011).

Recent studies on student learning have shown that initial levels of competence not only determine the learning growth rate but are also linked to the choice of academic tasks. Empirical findings suggest that beliefs of self-efficacy are an important predictor for the choice of tasks and the selection of courses, for instance in the areas of sport (Marsh et al., 2007; Sabiston and Crocker, 2008) and music (Austin, 1990; Simpkins et al., 2012), but also in the amount of leisure time given over to reading (Durik et al., 2006; Simpkins et al., 2012) and the number of math courses taken in high school (Simpkins et al., 2006; Simpkins et al., 2012). Cain and Oakhill (2011) illustrated these findings with the following example: "Poorer readers may choose to read less challenging books, ones that do not extend their current word reading or reading comprehension abilities. As a result, poor readers [...] have fewer opportunities to learn [...]" (Cain and Oakhill, 2011, p. 432).

Most adults encounter the opportunity to participate in adult education during their professional lives. Tight (1998) highlighted the exclusivity of the access that privileged groups of adults have to lifelong learning opportunities. He described this phenomenon with reference to the Matthew effect and considered it a possible cause of the reproduction of inequality in society. The unequal chances for participation in adult education also became apparent in large-scale, comparative international studies (Desjardins et al., 2006). Boeren (2009) has also been able to show, that within the European Union over a 12 month period, only $23.1 \%$ of low-skilled adults participated in adult learning, compared to $44.2 \%$ of medium-skilled and $68.7 \%$ of high-skilled adults. She concluded that participation in adult learning followed the Matthew effect: The unequal distribution of access to learning opportunities meant that adult education offerings were not reaching the intended target group, nor were they reducing educational inequality. A recent study by Bağ $\mathrm{Cl}$ (2019) provided further evidence for this claim. In her qualitative analysis, she was able to show that low levels of prior education are an almost perfect predictor of non-participation in formal learning.

In light of these findings, we aim to investigate whether the Matthew effect can also be found in the field of teacher training. We start in the following section by describing what characterises high quality teachers in general.

\section{What Defines a Skilled Teacher? Key Aspects of Teacher Quality}

The term 'teacher quality' has been used in the literature to describe a variety of aspects of teachers and teaching Kennedy (2010) points out that "we regularly confuse teaching quality with teacher quality, as if the two were indistinguishable" (p. 591). Indeed, a review of the literature shows that teacher quality tends to be used as an umbrella term for one or more of the following aspects: 1) teacher qualifications, 2) teacher characteristics, and 3) teaching practices. We therefore begin by defining each term and describing how these different aspects of teacher quality are related to teachers' engagement in PD.

The first of these aspects, teacher qualifications, refers in a narrow sense to teachers' university degrees, exam scores, or other formal certifications (Hairrell et al., 2011). Teachers' qualifications are often used as an indicator of teacher quality because they provide an easy means to measure both the quantity and quality of professional education. The use of such general markers has been criticised in the research, however, because they provide only generic information about the actual training received. Studies on the relationship between teachers' qualifications and student achievement have produced conflicting findings. Some studies have found that students achieve better learning outcomes with teachers who are 
certified in a particular subject than with uncertified teachers (Goldhaber and Brewer, 2000). Other studies have been unable to replicate these findings (Kane et al., 2008).

The second aspect, teacher characteristics, refers to aspects of an individual that are malleable and that can be learned through teacher training. European researchers refer to these characteristics as teachers' professional competence, which is comprised of professional knowledge as well as the attitudes and motivation required to master specific situations in the classroom (Baumert and Kunter, 2013). A number of studies have demonstrated that the concept of professional competence is useful for understanding teacher success and for predicting student achievement (Kunter et al., 2013b).

The third aspect of teacher quality is the quality of teaching practice. This aspect is strongly connected to how teachers organize their classes and how they teach, and is therefore one of the most important predictors of student learning (Hattie, 2010). The research on teaching quality has highlighted three dimensions as essential in initiating and maintaining meaningful learning processes: cognitive activation, classroom management, and student support (Seidel and Shavelson, 2007; Klieme et al., 2009; Pianta and Hamre, 2009). Cognitive activation focuses on fostering students' cognitive engagement and their ability to combine new knowledge with prior knowledge (Baumert et al., 2010). Classroom management, which includes effective classroom management activities, contributes to increased learning time and support and facilitates students' academic and social-emotional learning (Evertson and Weinstein, 2006). The student support dimension encompasses aspects of teaching that contribute to individual learning, such as a supportive learning climate and a positive student-teacher relationship (Reyes et al., 2012). All three dimensions have been explicitly linked to students' learning processes in the classroom (Kunter et al., 2013b; Holzberger et al., 2019). Using this broad classification of teacher quality, we now describe in more detail how these aspects of teacher quality relate to the uptake of professional learning opportunities.

\section{Which Teachers Participate in Professional Development?}

Professional development is an essential resource for teachers to deepen their knowledge and improve their practice (DarlingHammond et al., 2017; Thurlings and den Brok, 2017; Gheyssens et al., 2020), in order to close teacher quality gaps (Haycook and Crawford, 2008; Goldhaber et al., 2019). Recent studies have therefore examined teachers' personal characteristics more closely to attain a better understanding of what motivates or hinders individuals when it comes to participating in in-service training (Gorozidis and Papaioannou, 2014; Richter et al., 2018; Richter et al., 2019). Studies have also described the characteristics of participants in PD activities, for example, gender, age or school type (Krille, 2020). However, we still lack information on which teachers are more likely to access professional development opportunities. In the following literature review, we describe participants in professional development based on the characteristics of teacher quality discussed above. We understand teacher quality as a prerequisite for participation in $\mathrm{PD}$, although many studies have considered this relationship in reverse order, i.e. by investigating the effect of professional development on teacher quality (Yoon et al., 2007; Blank and las Alas, 2009; Meissel et al., 2016; Jacob et al., 2017).

\section{Teacher Qualifications}

A study on mathematics teachers in the United States examined the relationship between their highest university degree and the extent to which they engaged in sustained PD in mathematics (Desimone et al., 2006). The findings revealed that teachers with a higher-level degree in mathematics (undergraduate vs. graduate degree) were more likely to take part in sustained, content-focused PD than teachers with lower degrees, which implies that teachers who already have more in-depth content knowledge participate more frequently in PD activities that last longer and focus on their subject content.

\section{Teacher Characteristics}

We draw on the notion of teachers' professional competence as a conceptual framework for the large number of characteristics pertaining to teacher quality. This framework differentiates between four aspects of competence: teachers' knowledge, motivation, beliefs, and self-regulation (Baumert and Kunter, 2013). Studies have shown that apart from knowledge, all of these aspects are associated with the uptake of in-service training. Findings reveal that teachers who demonstrate more constructivist beliefs about learning tend to participate more frequently in PD (Richter et al., 2010). In another study, Nitsche et al. (2013) examined the role of teachers' goal orientations in the uptake of learning opportunities. The results showed that a learning goal orientation and performance goal orientation tend to be positive predictors of participation in PD. Furthermore, an Australian study suggested that for students of education, the initial motivation to teach predicts the likelihood of attending PD after completing their university education (Watt and Richardson, 2007; see also; Kunter and Holzberger, 2014). Another group of studies examined the relationships between teachers' self-regulation and the use of PD, finding a positive association between teachers' occupational engagement and taking advantage of PD activities (Richter et al., 2010; Watt et al., 2014).

\section{Teaching Practices}

Studies on the relationship between PD and teaching practice generally refer to how $\mathrm{PD}$ impacts the teaching practice of the teachers who attended particular programmes. Few studies have investigated what characterises the teaching practice of teachers who have or have not attended PD. Huffman et al. (2003) found a positive relationship between teachers' engagement in curriculum development and standardsbased instructional practices in mathematics and science. They conclude that teachers who are more skilled in standards-based practices tend to participate more frequently in this kind of PD. 


\section{Purpose of This Study}

The studies presented above have slightly indicated that the decision to attend in-service training correlates with different aspects of teacher quality. Taken together, the single studies consistently suggest some evidence that teachers with higher levels of quality are more likely to engage in PD. This observation is in line with what we know about the Matthew effect from research on participation in adult education (Boeren, 2009; Bağc1, 2019). If teachers' decisions to attend in-service training activities follow the Matthew effect, teachers who are highly qualified will tend to benefit more from professional learning opportunities than those who are less qualified. In this sense, PD would foster in particular the development of professional competence in a privileged group of teachers rather than supporting teachers who are less qualified and who would presumably benefit more from the PD (Desimone et al., 2006).

So far, research has not used a comprehensive framework to describe the professional characteristics of participants in PD. Such a framework seems to be necessary, however, in order to better understand the impact of the PD system. For this reason, the present study aims to provide new insights into why certain teachers invest substantial time in PD activities and others do not. We therefore focus on different aspects of teacher quality and investigate the relationship between these aspects and teachers' engagement in PD activities. Drawing on research on PD quality (Darling-Hammond et al., 2017) and following the procedure used by Desimone et al. (2006), we also take into account the type of PD in which teachers participated. We therefore differentiate between content-focused and noncontent-focused PD. We expect teachers with better qualifications, higher levels of professional competence, and better teaching practices to make more intensive use of PD offerings.

\section{MATERIALS AND METHODS}

\section{Study Design and Sample}

The present study builds on a secondary analysis of data collected between 2003 and 2004 as part of the COACTIV research project (Kunter et al., 2013a). The original study investigated relationships between secondary mathematics teachers' professional competence, instructional practice, and student achievement gains. COACTIV was part of PISA. The question posed by this secondary data analysis, however, was not the focus of the original study. Within this study, a nationally representative sample of ninth-grade students were selected. Students completed questionnaires asking for background data and aspects of their mathematics instruction. As part of COACTIV, the mathematics teachers of the participating classes also completed tests and questionnaires on aspects of their professional competence and their professional background.

The sample included 229 mathematics teachers with 240 classes and 4,517 students. The participating teachers had
21.0 years of teaching experience $(\mathrm{SD}=9.9)$ on average, and the majority were male (53.4\%). The teachers were selected from the academic and the non-academic school track. The academic track leads to a qualification that is required for university entry, while the non-academic track provides students with a qualification that is necessary for vocational training (Baumert et al., 2010). In the sample, $40.2 \%$ of teachers were from academic-track schools. The sample can be considered representative of mathematics teachers teaching in ninth-grade classrooms in Germany. The mean age of the students was 15.2 years, and the majority were male (56.2\%).

\section{Instruments}

\section{Teacher Qualifications}

We assessed teacher qualifications using the self-reported final grade teachers obtained during the practical phase of their initial teacher training. The average grade received by individuals at the end of teacher training can range from 1 to 5 , where 1 indicates the best performance and 5 the worst. We recoded the scores so that higher values represent better achievement.

\section{Teacher Characteristics}

We differentiated among professional knowledge, beliefs, motivation, and self-regulation skills as different aspects of teachers' professional competence (Baumert and Kunter, 2013). Below, we describe how each of the four characteristics was assessed.

\section{Professional Knowledge}

We used paper-and-pencil tests to assess teachers' content knowledge $(\mathrm{CK})$ and pedagogical content knowledge (PCK) in mathematics. The CK test consisted of 13 open-ended items that tested knowledge in different content areas relevant to ninthgrade mathematics (e.g. arithmetic). The items assessed the teachers' conceptual understanding of content from the secondary-level mathematics curriculum and required complex mathematical argumentations or proofs (Krauss et al., 2008; Krauss et al., 2013). The PCK test comprised 23 open-ended items. These questions tested teachers' knowledge of mathematical problems, student thinking, and explanations and representations.

The piloting of the CK and PCK tests followed a multistage procedure and included interviews, expert ratings of content validity, and extensive analyses of construct validity (Krauss et al., 2008; Krauss et al., 2013). Each item was independently coded by two trained raters who followed a standardised manual. Interrater agreement was satisfactory (Brennan, 2001), with a mean of $\rho=0.81$ (SD $=0.17$ ). Reliability as measured by the internal consistency of the two tests yielded a Cronbach's $\alpha=0.83$ for the CK scale and $\alpha$ $=0.77$ for the PCK scale. The bivariate correlation between the CK and PCK scores was $r=0.60$.

\section{Beliefs}

We assessed constructivist-oriented beliefs about teaching with a scale developed as part of the COACTIV research project (Voss 
et al., 2013). The scale uses 21 items, which were rated on a fourpoint response scale ranging from (1) strongly disagree to (4) strongly agree. The instrument measures the belief that student learning requires cognitively activating tasks and opportunities for students to converse about tasks and find alternative solutions. The scale comprised the three subscales mathematics as a process (four items, $\alpha=0.67$ ), discursive learning (12 items, $\alpha=0.88$ ), and mathematical independence (five items, $a=0.81$ ). Previous analyses showed that the three scales making up the constructivist-oriented belief can be reliably combined into a single factor representing a constructivist orientation (Voss et al., 2013).

\section{Motivation}

We assessed teachers' enthusiasm with a short, four-item scale developed in the COACTIV research project (Kunter et al., 2011) based on a validated questionnaire on teaching effectiveness (Marsh and Ware, 1982). The items focused on two subscales: teachers' enthusiasm for mathematics and teachers' enthusiasm for teaching. Both scales exhibited satisfactory reliability (subject enthusiasm: 2 items, $\alpha=0.69$; teaching enthusiasm: 2 items, $\alpha=$ 0.89 ). All items were rated on a four-point Likert scale ranging from (1) strongly disagree to (4) strongly agree.

\section{Self-Regulation}

Teachers' self-regulation was assessed using a short version of the Occupational Stress and Coping Inventory (Kieschke and Schaarschmidt, 2008), which uses four subscales to measure the dimensions of occupational engagement. Prompted by the instruction "We would like you to describe some of your typical behaviours, attitudes and habits with respect to your working life," teachers were asked to rate their agreement with each item on a five-point response scale ranging from (1) strongly disagree to (5) strongly agree. The scale was measured with a sufficient internal consistency of $\alpha=0.74$.

\section{Teaching Practices}

We assessed the quality of teaching practice along a widely used empirical framework for by Klieme et al. (2009) that includes three dimensions: Cognitive activation, classroom management, and student support. Cognitive activation was assessed with a teacher scale measuring the degree to which they set instructional tasks that engage students in higher order thinking processes (eight items, e.g. "In my lesson, I sometimes set problems that do not have a clear-cut solution and ask for explanations," recoded, $\alpha$ $=0.82$ ). Classroom management was assessed with a teacher scale measuring the effective use of time during instruction ( 8 items, e.g. "In this class a lot of time is wasted," $\alpha=0.93)$. Student support was assessed by students with a scale on the teacher's respectful interaction with students (three items, e.g. "Our mathematics teacher sometimes upsets students," recoded) (Löwen et al., 2013). As a reliability measure for the student ratings, we calculated intraclass correlations (ICC) (Lüdtke et al., 2007). ICC(2) coefficient was 0.74, indicating acceptable reliability (LeBreton and Senter, 2008). All items were rated on a four-point response scale ( $1=$ disagree, $4=$ agree $)$.

\section{Professional Development Activities}

In order to assess teachers' PD activities, the participating teachers were asked to list all courses, workshops, and conferences that they had attended during the previous two academic years (2001/2002 and 2002/2003). In addition, the teachers were asked to provide information about the duration of each activity. As part of the data analysis, two independent raters classified all 519 teachers' formal professional development activities into two categories: mathematics-specific (contentfocused) and other professional development (non-contentfocused, covering topics such as instructional strategies or school organisation and development). Interrater agreement was satisfactory (Landis and Koch, 1977), with $\kappa=0.80$. We identified $134 \mathrm{PD}$ activities (25.8\%) with a mathematical content focus. The average duration of all $519 \mathrm{PD}$ activities was $10.8 \mathrm{~h}$ (SD $=16.3$ ), and ranged from 2 to $250 \mathrm{~h}$.

\section{Teacher Background Characteristics}

We controlled for teachers' background characteristics that were likely to correlate with the dependent and independent variables in our study. Control variables included gender $(0=$ male, $1=$ female), teaching experience (in years), and school track $(0=$ non-academic track, 1 = academic track).

\section{Data Analyses}

To address our research question, we computed bivariate correlations between teacher quality and the time teachers who had participated in at least one PD activity invested in both content-focused and non-subject-focused PD over 2 years. Moreover, partial correlation analyses were conducted to examine the robustness of the results of the bivariate correlation analysis. In this analysis, we controlled for gender, teaching experience, and school track because these variables are likely to be associated with our independent variables.

\section{RESULTS}

Our research question addressed the relationship between the time teachers invest in content-focused vs. non-content-focused professional development activities. As shown in Table 1, the bivariate and partial correlations were moderate in size. Regarding teacher qualifications, the results reveal a significant positive correlation between average state examination grade and the number of hours in content-focused PD $(r=0.21)$. This relation remained significant after controlling for gender. Teachers with higher achievement in teacher training spent more time engaging in content-focused in-service training.

We also found significant correlations between the time invested in subject-focused $\mathrm{PD}$ and the following teacher characteristics: content knowledge $(r=0.26)$, pedagogical content knowledge $(r=0.18)$, constructivist orientation $(r=$ $0.22)$, motivation for mathematics $(r=0.26)$, and occupational engagement $(r=0.16)$. With the exception of pedagogical content knowledge, all correlations remained significant even after controlling for background characteristics. In other words, our 
TABLE 1 | Bivariate and partial correlations between teachers' background characteristics (gender, teaching experience, school track), teachers' professional competence, and the time (h) teachers invested in content-focused and non-content-focused PD activities

\begin{tabular}{|c|c|c|c|c|}
\hline & \multicolumn{2}{|c|}{ Time invested (h) in content-focused PD } & \multicolumn{2}{|c|}{ Time invested (h) in non-content-focused PD } \\
\hline & Bivariate correlation & Partial correlation $^{\mathbf{a}}$ & Bivariate correlation & Partial correlation \\
\hline \multicolumn{5}{|l|}{ Background characteristics } \\
\hline Gender $^{b}$ & 0.05 & - & -0.13 & - \\
\hline Teaching experience & -0.06 & - & -0.07 & - \\
\hline School track ${ }^{\mathrm{C}}$ & $0.20^{*}$ & - & 0.15 & - \\
\hline \multicolumn{5}{|l|}{ Teacher qualification } \\
\hline Teacher training average grade & $0.21^{\star}$ & $0.25^{\star}$ & 0.01 & 0.01 \\
\hline \multicolumn{5}{|l|}{ Teacher characteristics } \\
\hline PCK & $0.18^{*}$ & 0.10 & 0.15 & 0.13 \\
\hline $\mathrm{CK}$ & $0.26^{\star}$ & $0.26^{\star}$ & 0.13 & 0.13 \\
\hline Constructivist orientation & $0.22^{*}$ & $0.30^{\star}$ & 0.02 & -0.07 \\
\hline Enthusiasm for mathematics & $0.26^{\star}$ & $0.35^{\star}$ & -0.02 & 0.06 \\
\hline Occupational engagement & $0.16^{\star}$ & $0.39^{*}$ & 0.00 & -0.09 \\
\hline \multicolumn{5}{|l|}{ Teaching practices } \\
\hline Cognitive activation & $0.21^{*}$ & 0.17 & 0.05 & -0.02 \\
\hline Classroom management & -0.01 & -0.13 & 0.02 & -0.05 \\
\hline Student support & $0.24^{\star}$ & 0.18 & -0.04 & -0.13 \\
\hline
\end{tabular}

PCK, pedagogical content knowledge; CK, content knowledge.

${ }^{a}$ Control variables: gender, teaching experience, school track.

${ }^{b} \mathrm{O}=$ male, $1=$ female

${ }^{\circ} \mathrm{O}=$ non-academic, $1=$ academic.

${ }^{*} p<.05$ (two-tailed).

results indicate that teachers invest more time in content-focused PD if they have more in-depth content knowledge, hold more constructivist orientations, are more enthusiastic about mathematics, and show higher occupational engagement.

Concerning teaching practices, we found only bivariate correlations between the time invested in $\mathrm{PD}$ and both cognitive activation $(r=0.21)$ and student support $(r=0.24)$. After controlling for gender, the correlations were no longer significant. For this reason, the results provide only tentative evidence of a potential linkage between teachers' behaviour in the classroom and their uptake of content-related formal professional learning opportunities. Finally, we investigated the relationships between aspects of teacher quality and the time teachers invested in non-content-focused PD activities. No significant correlations were found as shown in Table 1.

\section{DISCUSSION}

Our study aimed to investigate the characteristics of participants in content-focused and non-content-focused PD activities. We concentrate on this distinction because many different studies-including correlational studies, quasi-experimental studies, longitudinal studies, and meta-analyses-demonstrate that PD activities that focus on subject-specific content, as opposed to very generic PD activities, contribute to PD effectiveness and support teacher learning (e.g., DarlingHammond et al., 2017).

We found a positive association between the time teachers invested in content-focused PD and different aspects of teacher quality. In detail, our results showed a positive relationship between the amount of invested time in content-focused PD and a teacher's average GPA in the practical phase of initial teacher training, which indicates that teachers who are already more proficient at the end of initial teacher training tend to invest more time in content-focused PD during their later career. This result supports findings by Desimone et al. (2006) revealing that teachers with higher levels of qualifications are likely to invest a greater amount of time in PD activities. Moreover, we also found a positive relationship between teachers' $P D$ activities and all aspects of teachers' professional competence (e.g. knowledge, beliefs), suggesting that teachers who already have the appropriate skills to support students' learning are more likely to participate in content-focused PD. These results are in line with prior findings (e.g. Richter et al., 2010; Watt et al., 2014) and also extend them, since no study has yet examined teacher knowledge (measured by reliable and valid tests) as a prerequisite for participation in $\mathrm{PD}$. We also found marginal evidence that teaching practice is positively related to the time teachers invest in content-focused PD, which is in line with Huffman et al. (2003). However, this relationship is not significant after controlling for teacher background (e.g. gender). It is likely that teaching quality related not only to teachers' uptake of PD activities but is also to other aspects such as teacher competence and student characteristics (Baumert et al., 2010; Fauth et al., 2019; Fauth et al., 2020). For this reason, follow-up studies could focus on mediating relationships between teacher participation in $\mathrm{PD}$, teacher skills, and instructional quality.

Aside from these findings, it appears that aspects of teacher quality are not related to the amount of time teachers invest in non-content-focused PD. Thus, we found no evidence for the 
Matthew effect for subject-independent PD activities. The missing relationships may be related to the fact that noncontent-focused PD includes a large variety of different topics such as teaching methods, school development, self-care, inclusion, media use etc. We conclude that the number of hours invested in these activities is not sufficiently informative for such analyses. Future studies should therefore focus primarily on the assessment of content-focused PD.

However, our results raise the question why aspects of teacher quality are associated with the use of content-focused PD. A frequently proposed explanation is that intensive use of highquality PD activities, such as content-focused PD, supports teachers' learning and thus leads to an increase in teacher quality. This idea has been supported by a number of studies on teachers' PD (Yoon et al., 2007; Blank and las Alas, 2009; Liu and Liao, 2019). In this sense, PD represents a learning opportunity for teachers that can foster improvements in teacher quality (Darling-Hammond et al., 2017). However, some studies indicate that many teachers have had poor experiences with the quality of PD (Darling-Hammond et al., 2009; Boston Consulting Group, 2015). In line with the assumption of a lack in quality in teacher PD, research has revealed that participation in $\mathrm{PD}$ is not necessarily associated with a development in teacher quality or instructional quality (Jacob et al., 2017). Moreover, little is known about how long the potential positive effects of participation in PD last. A recent study by Liu and Phelps (2019) suggested that the average gain from the program they evaluated was lost after just 37 days. For this reason, it seems necessary to discuss alternative explanations for the observed relationships.

A possible alternative explanation could be to understand teacher quality not as a consequence of participation in $\mathrm{PD}$, but as one of its causes (Desimone et al., 2006). What a teacher already knows and is able to do might be an important factor in their choice of a particular PD programme. This is consistent with findings on students' task choices (e.g., Simpkins et al., 2006; Simpkins et al., 2012), but also with findings from participation in adult education and corresponds with the Matthew effect (Desjardins et al., 2006; Boeren, 2009; Bağc1, 2019). The following example is based on Cain and Oakhill (2011) and illustrates this argument: a teacher with in-depth knowledge of advanced mathematics might be interested in a more challenging mathematics course than a teacher who has only basic mathematical skills and who may worry about not having sufficient background knowledge in mathematics to complete the course successfully. Teachers with advanced skills and knowledge in a given content area might therefore be more likely to engage in content-focused PD.

Due to our research design, we cannot provide clear evidence to support one of these two explanations. However, in accordance with our hypothesis and past research findings on Matthew effect, we consider the second explanation to be more plausible. Especially the finding that teachers who completed their teacher training with a better GPA spend more time taking part in content-focused $\mathrm{PD}$ is an indicator that participants in content-focused PD do not represent a random sample of all teachers. They may already be more open when it comes to PD and thus more capable of managing their classrooms prior to participation in the in-service training programmes.

A conceptual framework to explain the Matthew effect is the Expectancy-Value Theory (EVT) (Wigfield and Eccles, 2000; Eccles and Wigfield 2020). In general, EVT seeks to predict individuals' academic decisions, such as an adults' decision to participate in a PD activity, by means of two main determinants (Gorges, 2016). The first determinant is individuals' expectation of success, which represents their belief about whether their abilities are sufficient to accomplish a task. The second determinant is the perceived personal value of a task. This can refer to different aspects, such as experiencing enjoyment in fulfilling the task, the expected benefits of the task in the future or the subjective importance of doing the task well (Eccles, 2005). With reference to the present findings, it can be argued that highly proficient teachers have a higher expectation of success in completing a content-focused PD course than individuals who possess less proficient skills.

Although our findings are in line with the assumption of a Matthew effect in teacher PD, there may be additional reasons for the differential use of PD. For example, different scholars found that teachers' motivations for PD predict the uptake of professional development activities (Gorozidis and Papaioannou, 2014; Richter et al., 2019). Moreover, not only teacher motivations can predict participation in $\mathrm{PD}$, but also the characteristics of the PD opportunities themselves. Richter et al. (2020) demonstrate that both time and duration of PD courses significantly predict the participation rates. Finally, it is unclear to what extent teachers have equal access to PD. Particularly before the Covid-19 pandemic, PD programs were often provided as face-to-face meetings. They were bound to fixed locations and fixed times, which could be a factor in some teachers' inability to attend. In fact, teachers report that time constraints represent a major reason for not participating in PD opportunities (Richter et al., 2018).

\section{Limitations}

Although our study was based on a large, representative group of mathematics teachers from Germany, it has some limitations. First, due to the cross-sectional nature of our study, we are not able to establish a causal link between teacher quality and teachers' decisions to make use of in-service learning opportunities. Hence, future research should make use of a longitudinal research design in order to investigate the cause and effect of participation in PD. Therefore, future research needs to examine both the motivations that drive teachers to engage in additional PD and the effect of their participation with regard to teachers' learning, e.g. PCK and CK. In addition, we would also like to examine how the learning gains of the teachers in turn effect their classroom practice. In this context, it would be also interesting to track teachers' use of professional learning opportunities over a longer period and to identify different groups of users. Another limitation of our study is that our sample included only German mathematics teachers and the findings cannot be generalized to groups of teachers in other countries. We also considered only courses, workshops, and conferences in our analysis and did not consider informal 
learning opportunities. We would also like to point out that the data were collected between 2003 and 2004. Since then, however, there have been no significant reforms in the area of in-service teacher professional development in Germany, so it is reasonable to assume that the mechanisms of participation should be fundamentally comparable. Despite their age, however, they are of high quality for several reasons. For example, they include standardized competence tests of teachers and various facets of teacher quality. In addition, they combine teacher data and student data which can be linked directly to a particular teacher. With these limitations in mind, future research should attempt to recruit an international sample of teachers and investigate the uptake of both formal and informal learning opportunities.

\section{Implications}

This study provides evidence that more competent, that is, higher-quality teachers invest more time in content-focused PD compared to less competent. If teachers with higher levels of quality tend to take part in more content-focused PD activities, we have evidence of inequalities in the decision to make use of learning opportunities. These findings have implications for the research on PD as well as practical implications. Future research also needs to investigate the PD motivations of teachers with different levels of professional competence to better understand what drives them to take advantage of different learning opportunities. Moreover, further research needs to examine not only the relationship between teacher quality and the decision to make use of formal PD, but also the relationship between teacher quality and teacher learning in general. Such research will help to answer the question of how teacher quality can be improved.

The findings in this study also have a number of practical implications. If there is a Matthew effect in the PD system, this could contribute to widening the gap in teacher quality. Instead, we should strive for a PD system that supports all teachers in their development in order to ensure high quality teaching for all students. One possible way for policy makers to approach this goal could be to increase teacher participation in high-quality PD. For this to work, we first need a high-quality PD program (Desimone et al., 2006) provided by high-quality teacher educators (Liston et al., 2008; White, 2019). Secondly, we need to help those teachers who do not yet meet specific standards to identify potential areas for improvement as well as PD offerings

\section{REFERENCES}

Austin, J. R. (1990). The Relationship of Music Self-Esteem to Degree of Participation in School and Out-of-School Music Activities Among UpperElementary Students. Contrib. Music Educ. 17, 20-31. Available at: http://www. jstor.org/stable/24127467 (Accessed August 3, 2021).

Bast, J., and Reitsma, P. (1998). Analyzing the Development of Individual Differences in Terms of Matthew Effects in Reading: Results from a Dutch Longitudinal Study. Develop. Psychol. 34 (6), 1373-1399. doi:10.1037/00121649.34.6.1373

Baumert, J., Kunter, M., Blum, W., Brunner, M., Voss, T., Jordan, A., et al. (2010). Teachers' Mathematical Knowledge, Cognitive Activation in the Classroom, that fit their needs and help them to build up the skills they needed.

In summary, our study has given insight into the characteristics that are associated with higher participation in content-focused PD. Our findings are of particular importance for educational policy makers in Germany, as the German educational system requires all teachers to take part in some form of in-service training. This research is also relevant to current public discussions about how to improve students' educational outcomes by maintaining high teacher quality over the course of the career.

\section{DATA AVAILABILITY STATEMENT}

The data analyzed in this study is subject to the following licenses/ restrictions: The authors are not authorized to share data. Requests to access these datasets should be directed to Eric Richter, eric.richter@uni-potsdam.

\section{ETHICS STATEMENT}

Ethical review and approval was not required for the study on human participants in accordance with the local legislation and institutional requirements. The patients/participants provided their written informed consent to participate in this study.

\section{AUTHOR CONTRIBUTIONS}

ER: Conceptualization, Formal analysis, Investigation, Data Curation, Writing - Original Draft. MK: Methodology, Resources, Data Curation, Writing - Review \& Editing. AM: Writing - Review \& Editing, Supervision. DR: Conceptualization, Investigation, Methodology, Resources, Writing - Review \& Editing, Supervision.

\section{FUNDING}

The COACTIV study was supported by the German Research Foundation (BA1461/2-1 and BA1461/2-2). and Student Progress. Am. Educ. Res. J. 47 (1), 133-180. doi:10.3102/ 0002831209345157

Baumert, J., and Kunter, M. (2013). "The COACTIV Model of Teachers' Professional Competence," in Cognitive Activation in the Mathematics Classroom and Professional Competence of Teachers: Results from the COACTIV Project. Editors M. Kunter, J. Baumert, W. Blum, U. Klusmann, S. Krauss, and M. Neubrand (New York: Springer), 25-48. doi:10.1007/978-14614-5149-5_2

Bağcl, Ș. E. (2019). Migration and Participation in Adult Education: The Matthew Effect on Immigrants. Adult Educ. Q. 69 (4), 271-294. doi:10.1177/ 0741713619848108

Blank, R. K., and las Alas, N. de. (2009). The Effects of Teacher Professional Development on Gains in Student Achievement: How Meta Analysis Provides 
Scientific Evidence Useful to Education Leaders. Washington, DC: Council of Chief State School Officers. Available at: https://files.eric.ed.gov/fulltext/ ED544700.pdf (Accessed August 3, 2021).

Boeren, E. (2009). Adult Education Participation: The Matthew Principle. Filosofija Sociologija 20 (2), 154-161.

Boston Consulting Group (2015). Teachers Know Best: Teachers' Views on Professional Development. Available at: https://files.eric.ed.gov/fulltext/ ED576976.pdf (Accessed August 3, 2021).

Brennan, R. L. (2001). Generalizability Theory. New York, NY: Springer. doi:10.1007/978-1-4757-3456-0

Cain, K., and Oakhill, J. (2011). Matthew Effects in Young Readers. J. Learn. Disabil. 44 (5), 431-443. doi:10.1177/0022219411410042

Darling-Hammond, L., Hyler, M. E., and Gardner, M. (2017). Effective Teacher Professional Development. Palo Alto, CA: Learning Policy Institute. Available at: https://learningpolicyinstitute.org/sites/default/files/product-files/Effective Teacher_Professional_Development_REPORT.pdf (Accessed August 3, 2021).

Darling-Hammond, L., Wei, R. C., Andree, A., Richardson, N., and Orphanos, S. (2009). Professional Learning in the Learning Profession: A Status Report on Teacher Development in the United States and Abroad. Washington, DC: National Staff Development Council.

Desimone, L. M., Smith, T. M., and Ueno, K. (2006). Are Teachers Who Need Sustained, Content-Focused Professional Development Getting It? An Administrator's Dilemma. Educ. Adm. Q. 42 (2), 179-215. doi:10.1177/0013161X04273848

Desjardins, R., Rubenson, K., and Milana, M. (2006). "Unequal Chances to Participate in Adult Learning: International Perspectives," in Fundamentals of Educational Planning (Paris: Unesco, International Institute for Educational Planning), 83.

Durik, A. M., Vida, M., and Eccles, J. S. (2006). Task Values and Ability Beliefs as Predictors of High School Literacy Choices: A Developmental Analysis. J. Educ. Psychol. 98 (2), 382-393. doi:10.1037/0022-0663.98.2.382

Eccles, J. S. (2005). "Subjective Task Value and the Eccles et al. Model of Achievement-Related Choices," in Handbook of Competence and Motivation. Editors A. J. Elliot, and C. S. Dweck (New York, NY: Guilford Press), 105-121.

Eccles, J. S., and Wigfield, A. (2020). From Expectancy-Value Theory to Situated Expectancy-Value Theory: A Developmental, Social Cognitive, and Sociocultural Perspective on Motivation. Contemp. Educ. Psychol. 61, 101859. doi:10.1016/j.cedpsych.2020.101859

Eurydice (2008). Levels of Autonomy and Responsibilities of Teachers in Europe. Available at: https://op.europa.eu/de/publication-detail/-/publication/ b36880f0-c8be-4517-a3d0-e4a23dc6f323 (Accessed August 3, 2021).

Evertson, C. M., and Weinstein, C. S. (2006). "Classroom Management as a Field of Inquiry," in Handbook of Classroom Management: Research, Practice, and Contemporary Issues. Editors C. M. Evertson and C. S. Weinstein (New York, NY: Routledge), 3-15.

Fauth, B., Decristan, J., Decker, A.-T., Büttner, G., Hardy, I., Klieme, E., et al. (2019). The Effects of Teacher Competence on Student Outcomes in Elementary Science Education: The Mediating Role of Teaching Quality. Teach. Teach. Educ. 86, 102882. doi:10.1016/j.tate.2019.102882

Fauth, B., Wagner, W., Bertram, C., Göllner, R., Roloff, J., Lüdtke, O., et al. (2020). Don't Blame the Teacher? the Need to Account for Classroom Characteristics in Evaluations of Teaching Quality. J. Educ. Psychol. 112 (6), 1284-1302. doi:10.1037/edu0000416

Gheyssens, E., Consuegra, E., Engels, N., and Struyven, K. (2020). Good Things Come to Those Who Wait: The Importance of Professional Development for the Implementation of Differentiated Instruction. Front. Educ. 5 (96). doi:10.3389/feduc.2020.00096

Goldhaber, D. D., and Brewer, D. J. (2000). Does Teacher Certification Matter? High School Teacher Certification Status and Student Achievement. Educ. Eval. Pol. Anal. 22 (2), 129-145. doi:10.3102/01623737022002129

Goldhaber, D., Quince, V., and Theobald, R. (2019). Teacher Quality Gaps in U.S. Public Schools: Trends, Sources, and Implications. Phi Delta Kappan 100 (8), 14-19. doi:10.1177/0031721719846883

Gorges, J. (2016). Why Adults Learn: Interpreting Adults' Reasons to Participate in Education in Terms of Eccles' Subjective Task Value. Int. Online J. Educ. Teach. 3 (1), 26-41.

Gorozidis, G., and Papaioannou, A. G. (2014). Teachers' Motivation to Participate in Training and to Implement Innovations. Teach. Teach. Educ. 39, 1-11. doi:10.1016/j.tate.2013.12.001
Hairrell, A., Rupley, W. H., Edmonds, M., Larsen, R., Simmons, D., Willson, V., et al. (2011). Examining the Impact of Teacher Quality on Fourth-Grade Students' Comprehension and Content-Area Achievement. Reading Writing Q. 27 (3), 239-260. doi:10.1080/10573569.2011.560486

Harris, D. N., and Sass, T. R. (2011). Teacher Training, Teacher Quality and Student Achievement. J. Public Econ. 95 (7-8), 798-812. doi:10.1016/ j.jpubeco.2010.11.009

Hattie, J. (2010). Visible Learning: A Synthesis of over 800 Meta-Analyses Relating to Achievement (Reprint). London: Routledge.

Haycook, K., and Crawford, C. (2008). Closing the Teacher Quality Gap. Educ. Leadersh. 65 (7), 14-19.

Holzberger, D., Praetorius, A.-K., Seidel, T., and Kunter, M. (2019). Identifying Effective Teachers: The Relation Between Teaching Profiles and Students' Development in Achievement and Enjoyment. Eur. J. Psychol. Educ. 34 (4), 801-823. doi:10.1007/s10212-018-00410-8

Huffman, D., Thomas, K., and Lawrenz, F. (2003). Relationship Between Professional Development, Teachers' Instructional Practices, and the Achievement of Students in Science and Mathematics. Sch. Sci. Maths. 103 (8), 378-387. doi:10.1111/j.1949-8594.2003.tb18123.x

Jacob, R., Hill, H., and Corey, D. (2017). The Impact of a Professional Development Program on Teachers' Mathematical Knowledge for Teaching, Instruction, and Student Achievement. J. Res. Educ. Effect. 10 (2), 379-407. doi:10.1080/ 19345747.2016.1273411

Juel, C. (1988). Learning to Read and Write: A Longitudinal Study of 54 Children from First through Fourth Grades. J. Educ. Psychol. 80 (4), 437-447. doi:10.1037/0022-0663.80.4.437

Kane, T. J., Rockoff, J. E., and Staiger, D. O. (2008). What does certification tell us about teacher effectiveness? Evidence from New York City. Economics of Education Review 27 (6), 615-631. doi:10.1016/j.econedurev.2007.05.005

Kennedy, M. M. (2010). Attribution Error and the Quest for Teacher Quality. Educ. Res. 39 (8), 591-598. doi:10.3102/0013189X10390804

Kieschke, U., and Schaarschmidt, U. (2008). Professional Commitment and Health Among Teachers in Germany: A Typological Approach. Learn. Instruction 18 (5), 429-437. doi:10.1016/j.learninstruc.2008.06.005

Klieme, E., Pauli, C., and Reusser, K. (2009). "The Pythagoras Study: Investigating Effects of Teaching and Learning in Swiss and German Mathematics Classrooms," in The Power of Video Studies in Investigating Teaching and Learning in the Classroom. Editors T. Janik, and T. Seidel (Münster and New York: Waxmann), 137-160.

Krauss, S., Blum, W., Brunner, M., Neubrand, M., Baumert, J., Kunter, M., et al. (2013). "Mathematics Teachers' Domain-Specific Professional Knowledge: Conceptualization and Test Construction in COACTIV," in Cognitive Activation in the Mathematics Classroom and Professional Competence of Teachers: Results from the COACTIV Project. Editors M. Kunter, J. Baumert, W. Blum, U. Klusmann, S. Krauss, and M. Neubrand (New York: Springer), 147-174. doi:10.1007/978-1-4614-5149-5_8

Krauss, S., Brunner, M., Kunter, M., Baumert, J., Blum, W., Neubrand, M., et al. (2008). Pedagogical Content Knowledge and Content Knowledge of Secondary Mathematics Teachers. J. Educ. Psychol. 100 (3), 716-725. doi:10.1037/00220663.100.3.716

Krille, C. (2020). Teachers' Participation in Professional Development: A Systematic Review. Cham: Springer. doi:10.1007/978-3-030-38844-7

Kunter, M., Frenzel, A., Nagy, G., Baumert, J., and Pekrun, R. (2011). Teacher Enthusiasm: Dimensionality and Context Specificity. Contemp. Educ. Psychol. 36 (4), 289-301. doi:10.1016/j.cedpsych.2011.07.001

Kunter, M., and Holzberger, D. (2014). "Loving Teaching: Research on Teachers' Intrinsic Orientations," in Teacher Motivation: Theory and Practice. Editors P. W. Richardson, S. A. Karabenick, and H. M. G. Watt (New York, NY: Routledge), 83-99. doi:10.4324/9780203119273-6

Kunter M., J. Baumert, W. Blum, U. Klusmann, S. Krauss, and M. Neubrand (Editors) (2013a). Cognitive Activation in the Mathematics Classroom and Professional Competence of Teachers: Results from the COACTIV Project (New York: Springer). doi:10.1007/978-1-4614-5149-5

Kunter, M., Klusmann, U., Baumert, J., Richter, D., Voss, T., and Hachfeld, A. (2013b). Professional Competence of Teachers: Effects on Instructional Quality and Student Development. J. Educ. Psychol. 105 (3), 805-820. doi:10.1037/a0032583

Kwakman, K. (2003). Factors Affecting Teachers' Participation in Professional Learning Activities. Teach. Teach. Educ. 19 (2), 149-170. doi:10.1016/S0742-051X(02)00101-4 
Landis, J. R., and Koch, G. G. (1977). The Measurement of Observer Agreement for Categorical Data. Biometrics 33 (1), 159-174. doi:10.2307/2529310

LeBreton, J. M., and Senter, J. L. (2008). Answers to 20 Questions about Interrater Reliability and Interrater Agreement. Organizational Res. Methods 11 (4), 815-852. doi:10.1177/1094428106296642

Liston, D., Borko, H., and Whitcomb, J. (2008). The Teacher Educator's Role in Enhancing Teacher Quality. J. Teach. Educ. 59 (2), 111-116. doi:10.1177/0022487108315581

Liu, S., and Phelps, G. (2019). Does Teacher Learning Last? Understanding How Much Teachers Retain Their Knowledge after Professional Development. J. Teach. Educ. 71, 537-550. doi:10.1177/0022487119886290

Liu, Y., and Liao, W. (2019). Professional Development and Teacher Efficacy: Evidence from the 2013 TALIS. Sch. Effectiveness Sch. Improvement 30 (4), 487-509. doi:10.1080/09243453.2019.1612454

Löwen, K., Baumert, J., Kunter, M., Krauss, S., and Brunner, M. (2013). "The COACTIV Research Program: Methodological Framework," in Cognitive Activation in the Mathematics Classroom and Professional Competence of Teachers: Results from the COACTIV Project. Editors M. Kunter, J. Baumert, W. Blum, U. Klusmann, S. Krauss, and M. Neubrand (New York: Springer), 79-96. doi:10.1007/978-1-4614-5149-5_5

Lüdtke, O., Trautwein, U., Kunter, M., and Baumert, J. (2007). Reliability and Agreement of Student Ratings of the Classroom Environment: A Reanalysis of TIMSS Data. Learn. Environ Res 9 (3), 215-230. doi:10.1007/s10984-0069014-8

Marsh, H. W., Gerlach, E., Trautwein, U., Lüdtke, O., and Brettschneider, W.-D. (2007). Longitudinal Study of Preadolescent Sport Self-Concept and Performance: Reciprocal Effects and Causal Ordering. Child. Develop. 78 (6), 1640-1656. doi:10.1111/j.1467-8624.2007.01094.x

Marsh, H. W., and Ware, J. E. (1982). Effects of Expressiveness, Content Coverage, and Incentive on Multidimensional Student Rating Scales: New Interpretations of the Dr. Fox Effect. J. Educ. Psychol. 74 (1), 126-134. doi:10.1037/0022-0663.74.1.126

Meissel, K., Parr, J. M., and Timperley, H. S. (2016). Can Professional Development of Teachers Reduce Disparity in Student Achievement? Teach. Teach. Educ. 58, 163-173. doi:10.1016/j.tate.2016.05.013

Merton, R. K. (1968). The Matthew Effect in Science: The Reward and Communication Systems of Science are Considered. Science 159 (3810), 56-63. doi:10.1126/science.159.3810.56

Nitsche, S., Dickhäuser, O., Dresel, M., and Fasching, M. S. (2013). Zielorientierungen von Lehrkräften als Prädiktoren lernrelevanten Verhaltens. Z. für Pädagogische Psychol. 27 (1-2), 95-103. doi:10.1024/1010-0652/a000092

Petersen, A. M., Jung, W.-S., Yang, J.-S., and Stanley, H. E. (2011). Quantitative and Empirical Demonstration of the Matthew Effect in a Study of Career Longevity. Proc. Natl. Acad. Sci. USA 108 (1), 18-23. doi:10.1073/pnas.1016733108

Pianta, R. C., and Hamre, B. K. (2009). Conceptualization, Measurement, and Improvement of Classroom Processes: Standardized Observation Can Leverage Capacity. Educ. Res. 38 (2), 109-119. doi:10.3102/0013189X09332374

Reyes, M. R., Brackett, M. A., Rivers, S. E., White, M., and Salovey, P. (2012). Classroom Emotional Climate, Student Engagement, and Academic Achievement. J. Educ. Psychol. 104 (3), 700-712. doi:10.1037/a0027268

Richter, D., Kleinknecht, M., and Gröschner, A. (2019). What Motivates Teachers to Participate in Professional Development? an Empirical Investigation of Motivational Orientations and the Uptake of Formal Learning Opportunities. Teach. Teach. Educ. 86, 102929. doi:10.1016/j.tate.2019.102929

Richter, D., Kunter, M., Anders, Y., Klusmann, U., Lüdtke, O., and Baumert, J. (2010). Inhalte und Prädiktoren beruflicher Fortbildung von Mathematiklehrkräften. Empirische Pädagogik 24 (2), 151-168.

Richter, E., Marx, A., Huang, Y., and Richter, D. (2020). Zeiten zum beruflichen Lernen: Eine empirische Untersuchung zum Zeitpunkt und der Dauer von Fortbildungsangeboten für Lehrkräfte. Z. Erziehungswiss 23 (1), 145-173. doi:10.1007/s11618-019-00924-x

Richter, E., Richter, D., and Marx, A. (2018). Was Hindert Lehrkräfte an Fortbildungen Teilzunehmen? Z. Erziehungswiss 21 (5), 1021-1043. doi:10.1007/s11618-018-0820-4

Sabiston, C. M., and Crocker, P. R. E. (2008). Exploring Self-Perceptions and Social Influences as Correlates of Adolescent Leisure-Time Physical Activity. J. Sport Exerc. Psychol. 30 (1), 3-22. doi:10.1123/jsep.30.1.3
Scarborough, H. S., and Parker, J. D. (2003). Matthew Effects in Children with Learning Disabilities: Development of reading, IQ, and Psychosocial Problems from Grade 2 to Grade 8. Ann. Dyslexia 53 (1), 47-71. doi:10.1007/s11881-003-0004-6

Seidel, T., and Shavelson, R. J. (2007). Teaching Effectiveness Research in the Past Decade: The Role of Theory and Research Design in Disentangling Meta-Analysis Results. Rev. Educ. Res. 77 (4), 454-499. doi:10.3102/0034654307310317

Simpkins, S. D., Davis-Kean, P. E., and Eccles, J. S. (2006). Math and Science Motivation: A Longitudinal Examination of the Links between Choices and Beliefs. Develop. Psychol. 42 (1), 70-83. doi:10.1037/0012-1649.42.1.70

Simpkins, S. D., Fredricks, J. A., and Eccles, J. S. (2012). Charting the Eccles' ExpectancyValue Model from Mothers' Beliefs in Childhood to Youths' Activities in Adolescence. Develop. Psychol. 48 (4), 1019-1032. doi:10.1037/a0027468

Stanovich, K. E. (1986). Matthew Effects in Reading: Some Consequences of Individual Differences in the Acquisition of Literacy. Reading Res. Q. 21 (4), 360-407. doi:10.1598/RRQ.21.4.1

Thurlings, M., and den Brok, P. (2017). Learning Outcomes of Teacher Professional Development Activities: A Meta-Study. Educ. Rev. 69 (5), 554-576. doi:10.1080/00131911.2017.1281226

Tight, M. (1998). Lifelong Learning: Opportunity or Compulsion?. Br. J. Educ. Stud. 46 (3), 251-263. doi:10.1111/1467-8527.00082

Van Eekelen, I. M., Vermunt, J. D., and Boshuizen, H. P. A. (2006). Exploring Teachers' Will to Learn. Teach. Teach. Educ. 22 (4), 408-423. doi:10.1016/ j.tate.2005.12.001

Voss, T., Kleickmann, T., Kunter, M., and Hachfeld, A. (2013). "Mathematics Teachers' Beliefs," in Cognitive Activation in the Mathematics Classroom and Professional Competence of Teachers: Results from the COACTIV Project. Editors M. Kunter, J. Baumert, W. Blum, U. Klusmann, S. Krauss, and M. Neubrand (New York: Springer), 249-271. doi:10.1007/978-1-4614-5149-5_12

Walberg, H. J., and Tsai, S.-L. (1983). Matthew Effects in Education. Am. Educ. Res. J. 20 (3), 359-373. doi:10.3102/00028312020003359

Watt, H. M. G., and Richardson, P. W. (2007). Motivational Factors Influencing Teaching as a Career Choice: Development and Validation of the FIT-Choice Scale. J. Exp. Educ. 75 (3), 167-202. doi:10.3200/JEXE.75.3.167-202

Watt, H. M. G., Richardson, P. W., and Wilkins, K. (2014). Profiles of Professional Engagement and Career Development Aspirations Among USA Preservice Teachers. Int. J. Educ. Res. 65, 23-40. doi:10.1016/j.ijer.2013.09.008

White, S. (2019). Teacher Educators for New Times? Redefining an Important Occupational Group. J. Educ. Teach. 45 (2), 200-213. doi:10.1080/ 02607476.2018.1548174

Wigfield, A., and Eccles, J. S. (2000). Expectancy-Value Theory of Achievement Motivation. Contemp. Educ. Psychol. 25 (1), 68-81. doi:10.1006/ceps.1999.1015

Yoon, K. S., Duncan, T., Lee, S. W.-Y., Scarloss, B., and Shapley, K. (2007). Reviewing the Evidence on How Teacher Professional Development Affects Student Achievement: Issues \& Answers Report. REL 2007-No. 033. Available at: https://ies.ed.gov/ncee/edlabs/regions/southwest/pdf/REL_2007033_sum.pdf (Accessed August 3, 2021).

Conflict of Interest: The authors declare that the research was conducted in the absence of any commercial or financial relationships that could be construed as a potential conflict of interest.

Publisher's Note: All claims expressed in this article are solely those of the authors and do not necessarily represent those of their affiliated organizations, or those of the publisher, the editors and the reviewers. Any product that may be evaluated in this article, or claim that may be made by its manufacturer, is not guaranteed or endorsed by the publisher.

Copyright $\odot 2021$ Richter, Kunter, Marx and Richter. This is an open-access article distributed under the terms of the Creative Commons Attribution License (CC BY). The use, distribution or reproduction in other forums is permitted, provided the original author(s) and the copyright owner(s) are credited and that the original publication in this journal is cited, in accordance with accepted academic practice. No use, distribution or reproduction is permitted which does not comply with these terms. 